\title{
The Lc3-synthase gene B3gnt5 is essential to pre-implantation development of the murine embryo
}

\author{
Franziska Biellmann ${ }^{1}$, Andreas J Hülsmeier ${ }^{1}$, Dapeng Zhou ${ }^{3}$, Paolo Cinelli ${ }^{2}$ \\ and Thierry Hennet*1
}

\begin{abstract}
Address: ${ }^{1}$ Institute of Physiology and Zürich Center for Integrative Human Physiology, University of Zürich, Switzerland, ${ }^{2}$ Institute of Laboratory Animal Science, University of Zürich, Switzerland and ${ }^{3} \mathrm{MD}$ Anderson Cancer Center, University of Texas, 1515 Holcombe Blvd, Houston, TX 77030, USA

Email: Franziska Biellmann - fbiellmann@access.uzh.ch; Andreas J Hülsmeier - a.j.hulsmeier@access.uzh.ch;

Dapeng Zhou - dzhou@mdanderson.org; Paolo Cinelli - paolo.cinelli@ltk.uzh.ch; Thierry Hennet* - thennet@access.uzh.ch

* Corresponding author
\end{abstract}

Published: 12 November 2008

BMC Developmental Biology 2008, 8:109 doi:10.1186/147/-213X-8-109

Received: II June 2008

Accepted: 12 November 2008

This article is available from: http://www.biomedcentral.com/I47I-2I3X/8/109

(c) 2008 Biellmann et al; licensee BioMed Central Ltd.

This is an Open Access article distributed under the terms of the Creative Commons Attribution License (http://creativecommons.org/licenses/by/2.0), which permits unrestricted use, distribution, and reproduction in any medium, provided the original work is properly cited.

\begin{abstract}
Background: Glycosphingolipids (GSL) are integral components of mammalian cell membranes that are involved in cell adhesion and cell signaling processes. GSL are subdivided into structural series, like ganglio-, lacto/neolacto-, globo- and isoglo-series, which are defined by distinct trisaccharide cores. The $\beta I, 3 \mathrm{~N}$-acetylglucosaminyltransferase- $\mathrm{V}$ (B3gnt5) enzyme catalyzes the formation of the Lc3 structure, which is the core of lactoseries derived GSL.

Results: The biological significance of the glycoconjugates produced by the B3gnt5 enzyme was investigated by inactivating the $B 3 g n t 5$ gene in the mouse germline. The disruption of the B3gnt5 protein-coding region in mouse embryonic stem cells resulted in reduced Lc3-synthase activity, supporting its specific contribution to lactoseries derived GSL synthesis. Breeding of heterozygous mutant mice failed to produce any viable progeny homozygous for the B3gnt5-null allele. The genotypic examination of embryos from heterozygous crosses showed that the disruption of the $B 3 g n t 5$ gene leads to pre-implantation lethality. This finding was compatible with the expression pattern of the B3gnt5 gene in the pre-implantation embryo as shown by in situ hybridization. The analysis of GSL profiles in embryonic stem cells heterozygous for the B3gnt5-null allele confirmed the reduced levels of lactoseries derived GSL levels and of other GSL species.

Conclusion: The disruption of the B3gnt5 gene in mice affected the expression of lactoseries derived GLS and possibly of protein-bound $\beta 3$ GlcNAc-linked glycans, thereby demonstrating an essential contribution of these glycoconjugates in early embryonic development, and supporting the importance of these glycoconjugates in cell differentiation and adhesion processes.
\end{abstract}

\section{Background}

Glycosphingolipids (GSL) represent a large family of glycoconjugates, which are found abundantly on cellular membranes. GSL are classified into different series defined by their respective core structures. In vertebrates, the main GSL series are called ganglio-, lacto-, globo-, isoglobo-, and muco-series [1]. The functional significance of GSL is diverse since these glycoconjugates have been implicated in processes such as cell adhesion, cell migration, regulation of signaling proteins and binding of 
pathogens and toxins [2,3]. The repertoire of GSL expressed by an organism is subject to changes according to cell type and developmental stage. Consequently, several stem cell and differentiation markers of early embryonic development, such as the stage-specific embryonic antigens SSEA-1, -3 and -4, represent carbohydrate epitopes carried by GSL [4-6].

The diversity of GSL is shaped by the action of multiple glycosyltransferase enzymes localized in the Golgi apparatus. The inactivation of key glycosyltransferase genes allows investigation of the functional specificity of individual GSL structures or of a whole GSL series. The $\beta 1,3 \mathrm{~N}$ acetylglucosaminyltransferase-V (B3gnt5) enzyme initiates the formation of the lactoseries GSL by transferring GlcNAc in a $\beta 1,3$-linkage to lactosylceramide. This transfer event leads to the synthesis of the Lc3 structure (Fig. 1) $[7,8]$. The B3gnt5 gene is expressed during mouse development and then again later mainly in the spleen and pla-

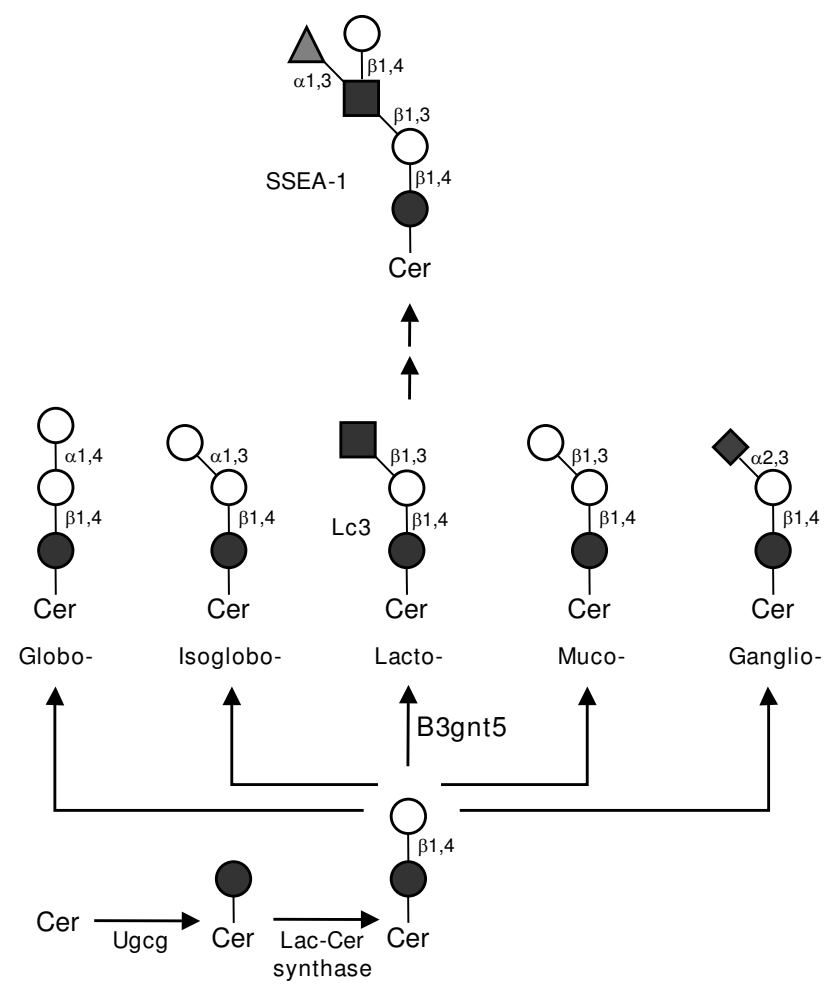

Figure I

Biosynthesis of GSL core structures. GSL biosynthesis is initiated by the transfer of Glc to ceramide (Cer) catalyzed by the Ugcg enzyme. After addition of $\beta$ I,4-linked Gal by Lac-Cer synthase, distinct core structures are defined by the action of different glycosyltransferases. The B3gnt5 enzyme catalyzes the Lc3 structure, which is the core of lactoseries GSL. The elongation of Lc3 by a $\alpha$ l,3-fucosyltransferase and a $\beta$ I,4-galactosyltransferase yields the SSEA-I antigen. 1, Glc; m, Gal; n, GlcNAc; r Sia; s, Fuc. centa in adult mice. Additionally B3gnt5 transcripts are found in the adult mouse brain where B3gnt5 expression is limited to cerebellar Purkinje cells [7].

The B3gnt5 enzyme has been shown to be key in the expression of sulfoglucuronylglycolipids (SGGL) in the developing nervous system [9]. SGGL are expressed in a regulated manner during embryonic brain development and again postnatally [10-13]. For example, SGGL carry the HNK-1 epitope, which has been implicated in the regulation of synaptic plasticity $[14,15]$. In addition, the developmentally regulated expression of SGGL coincides with certain cell migration and differentiation phases [16].

The B3gnt5 enzyme also initiates the formation of the SSEA-1 epitope, which is identical to the Lewis X antigen. SSEA-1 corresponds to the trisaccharide Gal $\beta 1,4$ (Fuc 1,3 )GlcNAc which is first found on 8-cell stage embryos and in mouse embryonic stem (ES) cells [17]. The SSEA-1 epitope, which is mainly found on lactoseries derived GSL, is believed to participate in the regulation of cell adhesion during embryogenesis, cell differentiation, and development of the neuronal system $[4,18]$. In order to study the developmental and physiological processes mediated by lactoseries derived GSL, we have inactivated the B3gnt5 gene in mice by homologous recombination in ES cells. This mouse model suggests an essential contribution of the lactoseries derived GSL series in the very early stages of mouse development.

\section{Results}

To address the functional role of the B3gnt5 gene in mouse development and physiology, we inactivated this gene by homologous recombination in mouse ES cells. The B3gnt5 targeting vector (Fig. 2A) was electroporated into R1 and TC1 ES cells. After selection with G418 and screening of 300 cell clones, we identified four ES cell clones bearing the homologous recombined allele. The homologous recombination at the B3gnt5 locus was confirmed using both PCR and genomic Southern blot analysis. The genomic Southern probe distinguished between the wildtype and the null allele by producing diagnostic EcoRI fragments of $3 \mathrm{kbp}$ and $2.3 \mathrm{kbp}$, respectively (Fig. $2 \mathrm{~B})$. The absence of chromosomal aberrations was verified by karyotyping the four homologously recombined ES cells (data not shown).

The inactivation of the B3gnt5 gene was confirmed by measuring the level of $\mathrm{N}$-acetylglucosaminyltransferase activity in targeted ES cells. The enzymatic activity towards the artificial acceptor $\operatorname{Gal}(\beta 1-0)$ p-nitrophenol and towards lactosylceramide was assayed in wildtype and in B3gnt5-targeted ES cells. The transfer of GlcNAc to Gal $(\beta 1$ 0)p-nitrophenol was reduced in R1 and in TC1 B3gnt5- 
A
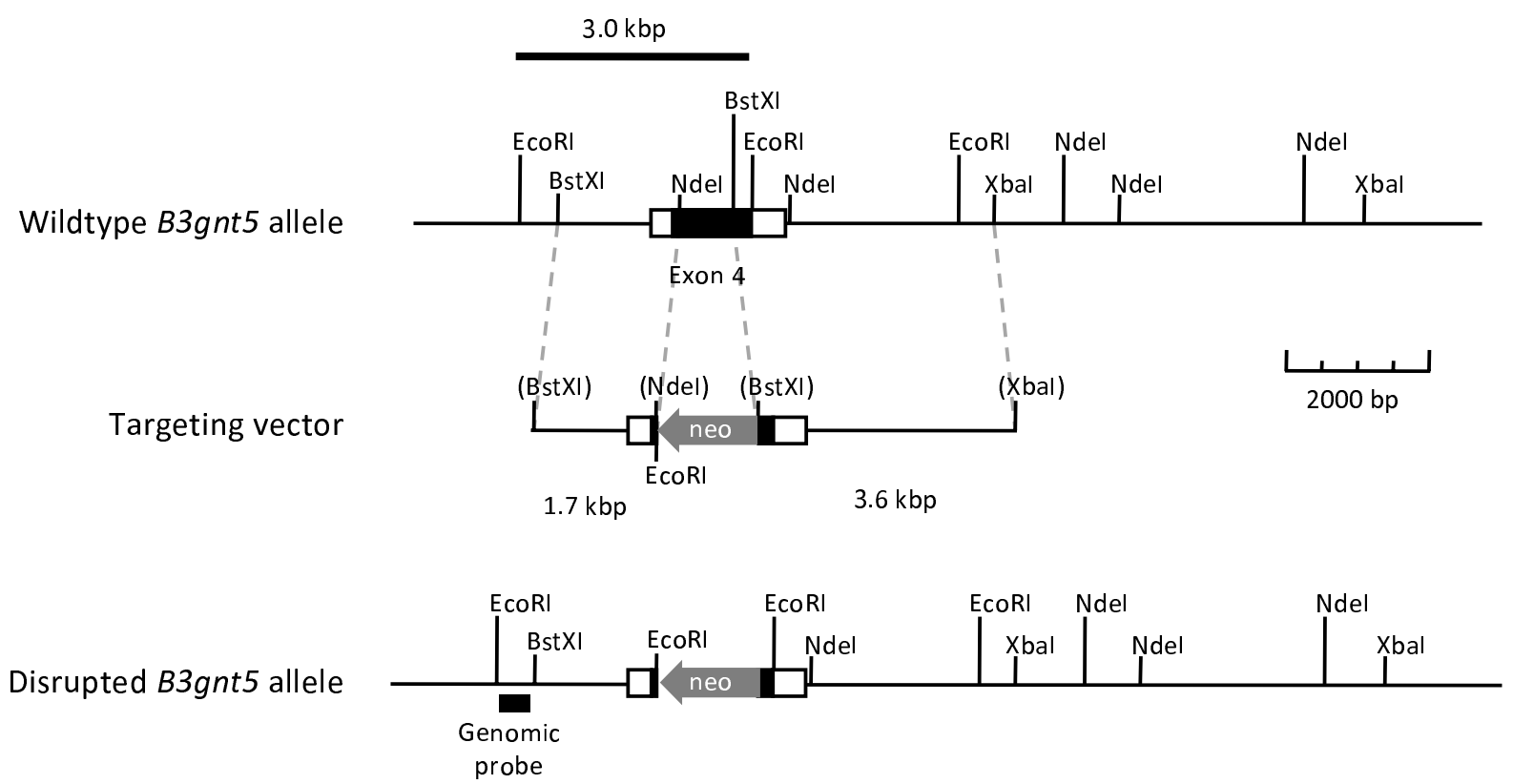

$$
2.3 \mathrm{kbp}
$$

B

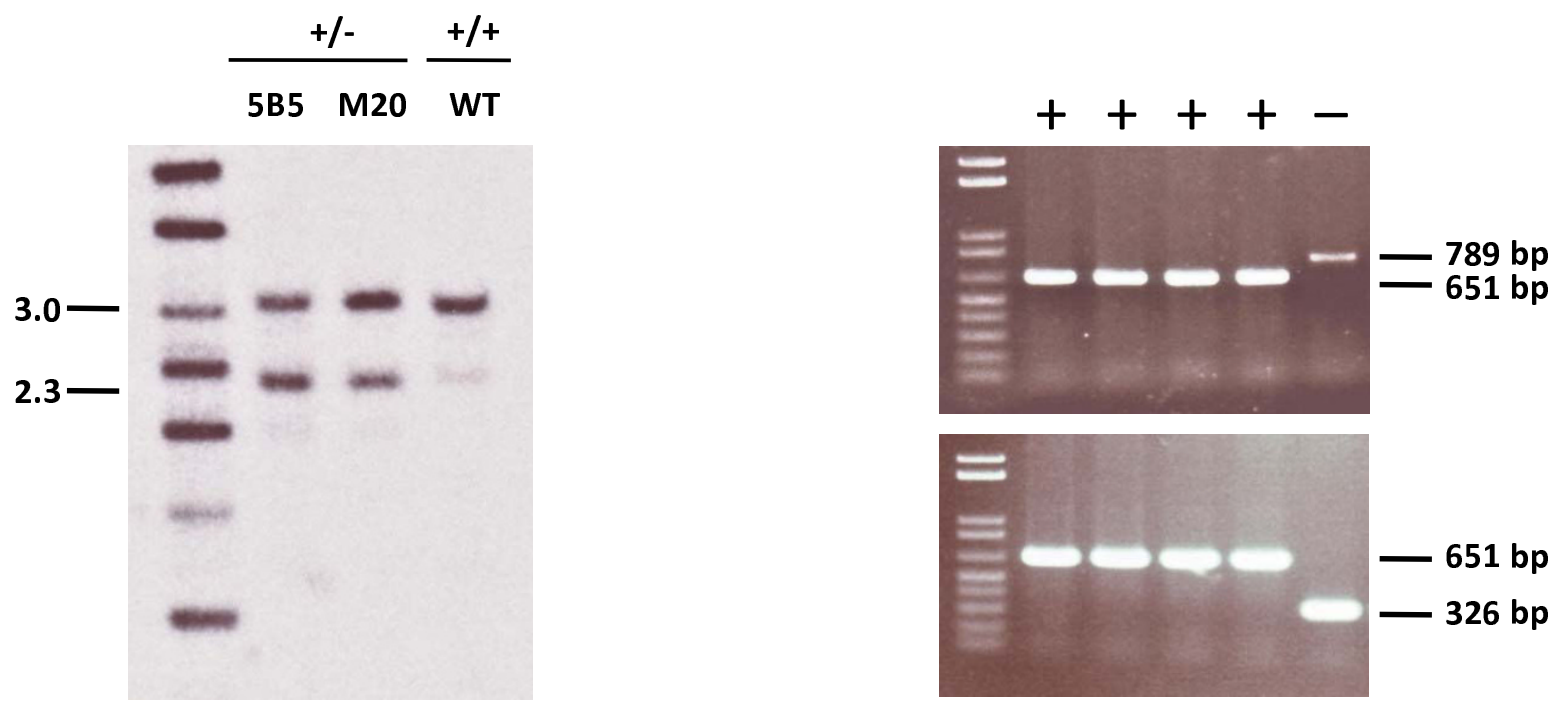

Figure 2

B3gnt5 gene targeting in ES cells. A. The targeting vector was produced by cloning a neo resistance cassette into exon 4 of the mouse B3gnt5 gene. The construct was flanked by two genomic arms of $I .7$ and $3.6 \mathrm{kbp}$. A genomic probe located just outside of the targeted region was used to detect homologous recombination. B. Genomic Southern blotting of ES cell clones. Genomic DNA of wildtype (WT) ES cells and of two ES cell clones bearing a homologously recombined B3gnt5 allele (5B5 and M20) were digested with EcoRI and hybridized to the genomic probe. C. Genotyping of wildtype (+) and targeted (-) B3gnt5 alleles by PCR as described in the Materials and Methods section. 
targeted ES cells, but did not reached $50 \%$ of the activity measured in wildtype cells (Fig. 3). When using lactosylceramide, the physiological acceptor of the B3gnt5 enzyme, the $\mathrm{N}$-acetylglucosaminyltransferase activity detected in the targeted ES cells was indeed reduced to $50 \%$ of the normal levels this demonstrating the loss of a functional B3gnt5 allele.

The four ES cell clones bearing the B3gnt5-null allele were injected into C57BL/6 blastocysts to produce chimeric offspring. Two male chimeric founders were obtained from the blastocysts microinjected with the two R1 ES cell clones, whereas the microinjection of TC1 ES cells did not yield any viable offspring. The chimeric males were mated with wildtype $\mathrm{C} 57 \mathrm{BL} / 6$ females and the $\mathrm{F} 1$ progeny screened with PCR for germ line transmission of the disrupted allele. Both chimeric males transmitted the null allele to their progeny. Offspring positive for the disrupted gene were backcrossed onto the C57BL/6 background for five generations. All the heterozygous offspring obtained from the chimeric males were grossly normal. Both male and females carriers of the null allele were obtained. Heterozygote mice were then bred to produce homozygous-null offspring. After crossing 17 independent heterozygote breeding pairs, no homozygousnull offspring were detected (Table 1 ). The ratio of wildtype to heterozygous-null mice was $34 \%$ to $66 \%$, thus corresponding to a Mendelian allele distribution assum-

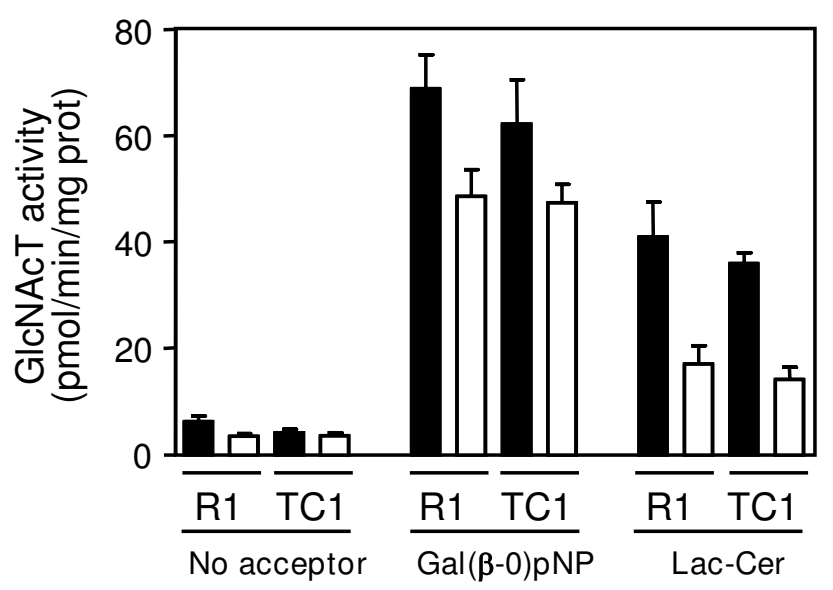

Figure 3

$\mathbf{N}$-acetylglucosaminyltransferase activity in ES cells. ES cells of the RI and TCI lines were lysed and N-acetylglucosaminyltransferase (GlcNAcT) activity was measured towards the acceptor substrates $\mathrm{Gal}(\beta-0)$ p-nitrophenol (pNP) and lactosylceramide (Lac-Cer). Black bars show GlcNAcT activity of wildtype ES cells and open bars show GIcNAcT activity of B3gnt5-targeted ES cells. Each value represents the average + S.D. of three independent measurements. ing a complete lethality of homozygous-null offspring. Since the expression of the B3gnt5 gene was shown to be elevated in embryos by mid-gestation [7], we genotyped 69 embryos isolated at E10 to assess whether homozygous-null embryos could be detected. The size and morphology of the embryos isolated at that stage were normal (data not shown) and the genotypic analysis demonstrated that $29.1 \%$ and $70.9 \%$ of embryos were wildtype and heterozygous-null, respectively (Table 1). Notably, no sites of resorption were observed in the uteri examined at mid-gestation. To identify whether the lack of embryonic development in B3gnt5-null mice was related to an implantation defect, we setup time-matings of heterozygous-null mice and examined the genotype of resulting embryos at the blastocyst stage. Again, no homozygous-null embryos were detected (Table 1), thereby indicating that the B3gnt5 gene is required for blastocyst development.

Since no homozygous-null embryos could be recovered, we analyzed the expression pattern of B3gnt5 in preimplantation embryos to confirm that the gene was indeed expressed during early embryogenesis. In situ hybridization showed the presence of the B3gnt5 transcript already at the 2-cell stage. The expression was uniform in all embryonic stages up to the morula stage. In blastocysts, B3gnt5 expression was confined to the inner cell mass, as no signal was observed in trophoblast cells (Fig. 4). The expression of the B3gnt5 gene throughout early embryogenesis was compatible with the finding of a pre-implantation lethality in B3gnt5-null mice.

The inner cell mass of blastocysts is the source of ES cells used for gene targeting. Accordingly, we examined the level of B3gnt5 gene expression in the R1 and TC1 ES cells by quantitative PCR. The B3gnt5 mRNA levels were identical in the two cell lines and comparable to the expression of the housekeeping Polr2a polymerase gene (data not shown). Because the B3gnt5 enzyme is involved in the biosynthesis of the lactoseries derived GSL, we also analyzed GSL profiles quantitatively in wildtype and in B3gnt5-targeted R1 and TC1 ES cells. GSL were isolated from ES cells by organic solvent extraction and digested by ceramide glycanase to release the carbohydrate moiety. The resulting oligosaccharides were labeled with 2-aminobenzamide at their reducing end and separated by HPLC [19]. The comparison between wildtype and B3gnt5-targeted ES cells showed decreased amounts of several GSL structures (Fig. 5A). The lactoseries GSL Lc3, the product of the B3gnt5 enzyme, was not detected in ES cells. However, its elongation products, the lactoseries derived Lc5 and Lc6 were identified and found to be present at lower levels in B3gnt5-targeted ES cells. The decreased amounts of GSL found in B3gnt5-targeted ES cells were not limited to lacto-series GSL, since the gan- 
Table I: Genotype analysis of B3gnt5 heterozygous crosses at various stages of murine development

\begin{tabular}{lcccc}
\hline Developmental Stage & WT (+/+) & Het (+/-) & KO (-l-) & Total screened \\
\hline Blastocyst (E3.5) & $20.8 \%$ & $79.2 \%$ & 0 & 48 \\
Embryo (EIO) & $29.1 \%$ & $70.9 \%$ & 0 & 69 \\
Viable pups & $34 \%$ & $66 \%$ & 0 & 205 \\
\hline
\end{tabular}

gliosides GM3, GM1, GD1 and the globosides Gb3, Gb5 were also reduced. The identity of the oligosaccharide structures detected by HPLC was confirmed by mass-spectrometry. The oligosaccharide sequences were further examined by fragmentation analysis (Fig. 5B). This analysis of GSL profiles on ES cells demonstrated the contribution of the B3gnt5 enzyme to the formation of lactoseries derived GSL.

\section{Discussion}

By disrupting the B3gnt5 gene, we aimed to improve current appreciation of the functions of lactoseries derived GSL in vivo. Our study suggests an essential role of this GSL series in pre-implantation embryonic development by showing that B3gnt5-null blastocysts could not be retrieved from heterozygous matings. The expression of the B3gnt5 gene from the two-cell stage up to the blastocyst stage would suggest a role for lactoseries derived GSL in cell-cell adhesion, possibly contributing to embryo compaction and implantation. Similarly, the SSEA- 1 antigen has been shown to mediate the tight adhesion of blastomeres, since the addition of multivalent SSEA-1 structures promotes embryo decompaction [20]. The formation of the SSEA-1 antigen requires the action of the $\alpha 1,3$ fucosyltransferase FUT9 [21]. The disruption of the Fut9 gene in mice abolished the formation of the SSEA-1 antigen in pre-implantation embryos, but this loss did not affect the compaction and implantation processes [18]. This finding showed that the fucose residue is critical for marking the antigen but that fucose is dispensable for the potential adhesion properties of the lactoseries derived structure.

The early lethality observed in the B3gnt5 gene disruption model contrasts with the phenotype described for mice lacking the ceramide glucosyltransferase Ugcg gene, which initiates GSL biosynthesis (Fig. 1). Ugcg homozygous-null embryos have been reported to die between embryonic days E7.5 and E9.5 [22]. Since Ugcg activity is required for the formation of lactoseries derived GSL, the reverse order would be expected for the onset of lethality in the Ugcg and B3gnt5 gene disruptions. A similar paradoxical situation was observed in the globoside GSL pathway when comparing the phenotypes resulting from the disruptions of the $\alpha 1,4$ galactosyltransferase Gb3-synthase [23] and $\beta 1,3 \quad \mathrm{~N}$-acetylgalactosaminyltransferase Gb4-synthase [24] genes. Mice lacking the Gb3-synthase gene developed normally and did not show any physiological abnormal-

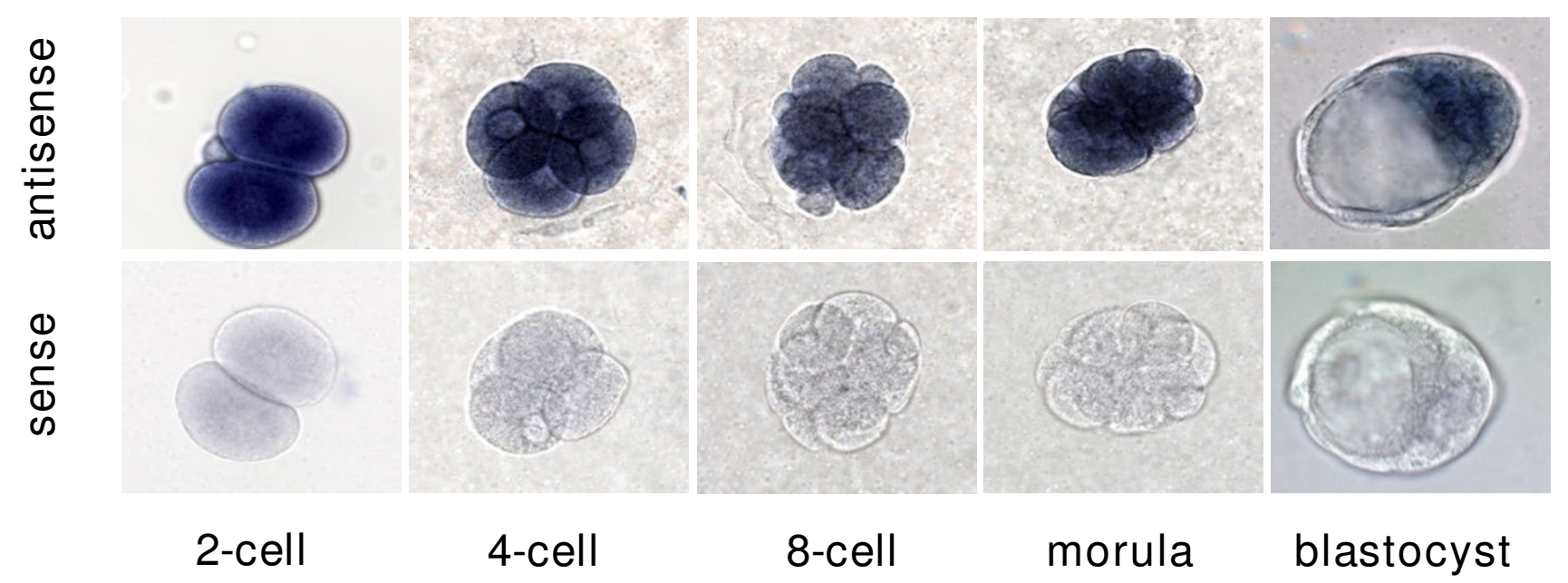

\section{Figure 4}

B3gnt5 expression in pre-implantation embryos. All pre-implantation stages investigated show the uniform presence of B3gnt5 transcripts up to the morula stage. B3gnt5 transcripts were confined to the inner cell mass at the blastocyst stage. Sense and antisense RNA probes were DIG-labeled as described in the Materials and Methods section. The pictures show embryos taken from C57BI/6 wildtype matings. 
A

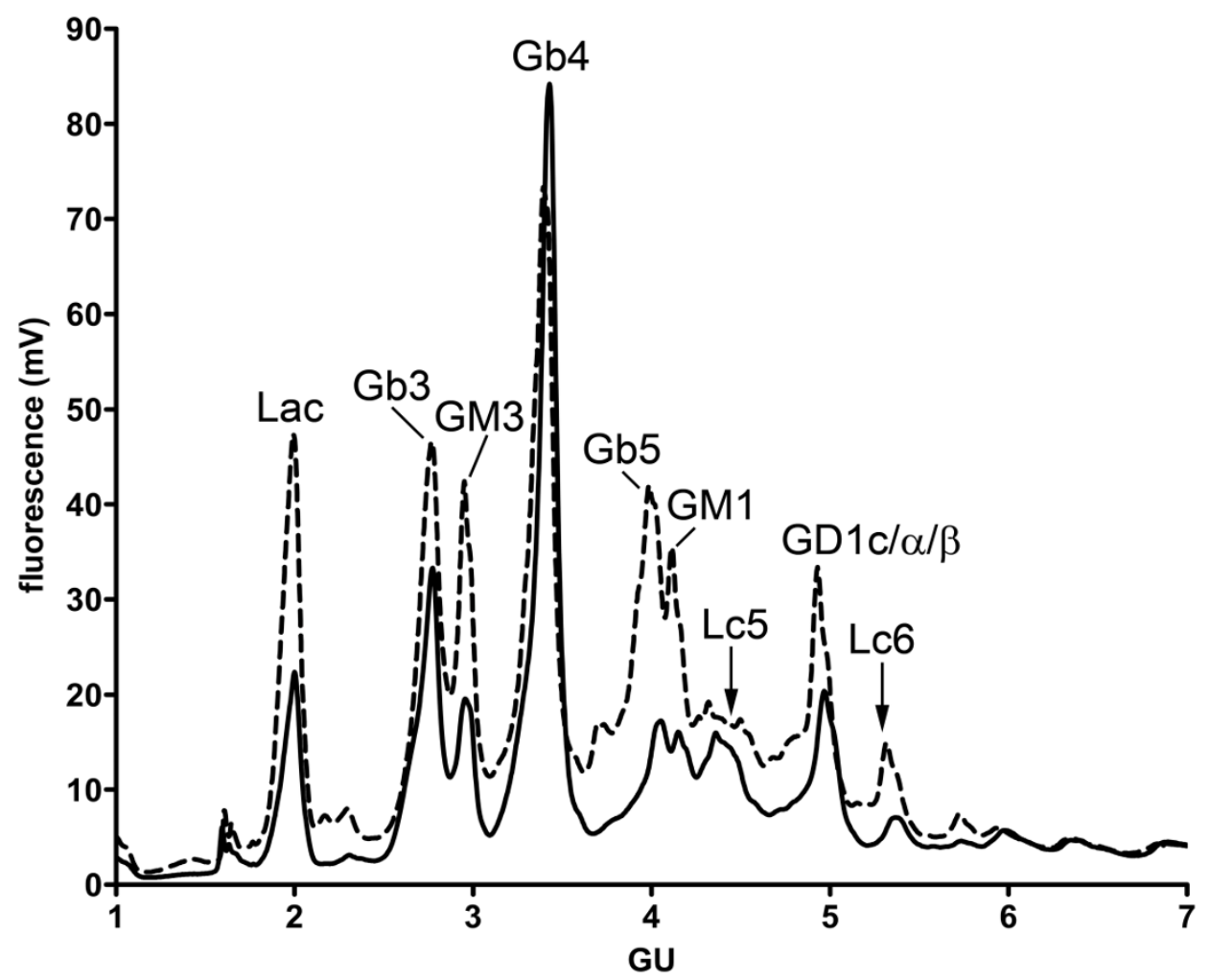

B

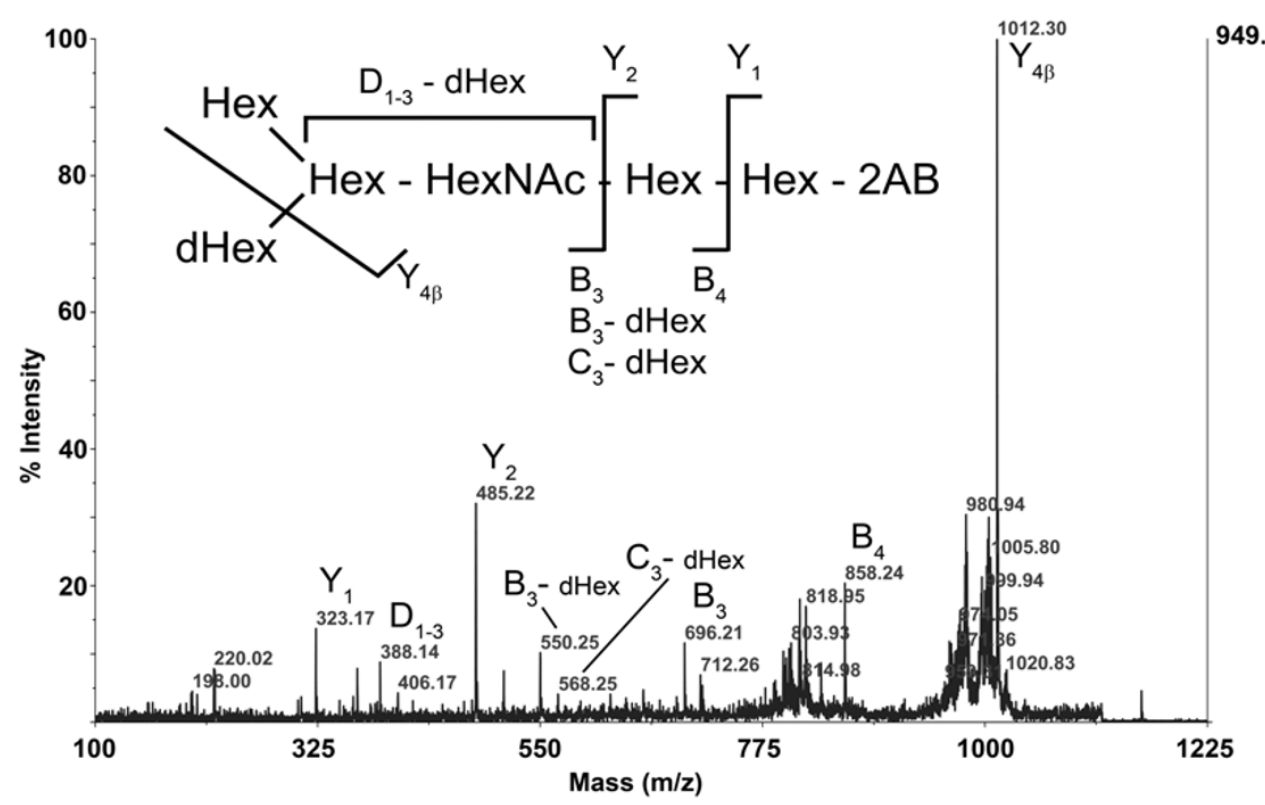

Figure 5

Glycolipid analysis in ES cells. A. The oligosaccharide moiety of ES cell GSL was cleaved by ceramide glycanase, labeled with 2-aminobenzamide and separated by normal phase HPLC. The retention times of glucose units (GU) is indicated on the $x$ axis. The dotted line shows the GSL profile of wildtype RI ES cells and the plain line shows the GSL profile of the RI clone 5B5. B. Mass spectrometric fragmentation spectrum of the Lc6 oligosaccharide obtained from the corresponding HPLC fraction. The main fragment ions are labeled and their assignment to the Lc6 structure is depicted. 
ity [25]. By contrast, the disruption of the Gb4-synthase gene arrested development at the blastocyst stage and prevented the implantation of mouse embryos [26]. This apparent discrepancy may have different causes. It is possible that the loss of Ugcg activity is compensated for by other glycosyltransferase activities expressed during preimplantation stages. However, no glycosyltransferase has been described with such activity yet and no proteins similar to the Ugcg enzyme could be retrieved from the mouse genome so far. Alternatively, it is possible that the expression of the Ugcg gene in unfertilized oocytes [27] yields enough of the Ugcg enzyme to sustain the formation of Glc-Cer until gastrulation.

The enzymatic characterization of the B3gnt 5 protein has shown a significant $\mathrm{N}$-acetylglucosaminyltransferase activity towards the monosaccharide Gal [7]. Therefore it is conceivable that B3gnt5 may act on Gal-termini found on $\mathrm{N}$ - or O-linked glycans. However, it is likely that preimplantation lethality is in fact mediated by a defect of GSL biosynthesis, since defects in N- or O-linked glycan elongations lead to post-implantation lethal phenotypes at the earliest [28]. Indeed, the inactivation of the B3gnt2 gene, a paralog of B3gnt 5 that mediates the formation of poly-N-acetyllactosamine chains on glycoproteins, does not impair embryonic development [29].

Even if the pre-implantation lethality observed in the B3gnt5-null embryos is caused by a defect of GSL biosynthesis, the question remains whether the loss of B3gnt5 solely affects the lactoseries derived GSL pathway. Our analysis of GSL profiles in ES cells bearing a B3gnt5-null allele showed decreased levels of additional GSL structures, such as the gangliosides GM3, GM1, GD1 and the globosides Gb3, Gb5 (Fig. 5). Earlier work has documented the physical interaction of glycosyltransferases involved in GSL biosynthesis [30], suggesting that the loss of a single enzyme might destabilize the localization and thereby the activity of other enzymes.

\section{Conclusion}

The disruption of the B3gnt5 gene leads to the earliest lethality reported for a Golgi-localized glycosyltransferase, thereby underlining the essential role of lactoseries derived GSL and possibly of protein-bound $\beta 3$ GlcNAclinked glycans in pre-implantation embryogenesis. Because of this early lethality, the role of these glycoconjugates in subsequent developmental pathways could not be determined in the present model. The expression pattern of the B3gnt5 gene at gastrulation and at later stages would support the involvement of B3gnt5 products in processes such as neurogenesis and brain development. The production of a conditional B3gnt5 gene targeting model will certainly bring new insights on the role of lactoseries derived GSL in organ development and functions.

\section{Methods \\ B3gnt5 gene targeting}

The targeting vector was assembled by flanking the PGKNeo cassette of the pPGK-Neo plasmid [31] with two fragments of $129 \mathrm{~Sv} / \mathrm{J}$ genomic DNA fragments isolated from a $\lambda$ FIX-II bacteriophage library (Stratagene). The left arm, a 1.7-kbp BstXI-NdeI fragment that includes $400 \mathrm{bp}$ of the B3gnt5 exon 4, was inserted blunt-end into the NotI site of pPGK-Neo and the right arm of the targeting vector was subcloned blunt-end as a 3.6-kbp BstXI-XbaI fragment into the EcoRV site of pPGK-Neo. Using this construct, a stretch of 745 bp encoding the catalytic domain of B3gnt5 was replaced by the PGK-Neo cassette (Fig. 2A). The targeting vector was linearized at the unique Sac II site and $10 \mu \mathrm{g}$ were electroporated into $5 \times 10^{6}$ mouse embryonic stem (ES) cells of line R1 [32] and TC1 [33]. Cells were seeded on gelatin-coated Petri dishes and cultured in $\mathrm{KO}$ DMEM (Gibco) containing 15\% fetal calf serum (Gibco), $1000 \mathrm{U} / \mathrm{ml}$ leukemia inhibitory factor (ESGRO, Gibco) and G418 $(200 \mu \mathrm{g} / \mathrm{ml})$. After 5 days of selection, 300 clones were picked and tested for homologous recombination by PCR and genomic Southern blotting.

\section{Genotyping of ES cell clones}

Homologously recombined B3gnt5 alleles were identified by PCR amplification of a 1920-bp fragment comprising the boundary of PGK-Neo up to the genomic DNA proximal to the left arm of the targeting vector. The PCR reaction was carried out using 50 ng of genomic DNA with the primers 5'-TACTACCCTGTCTAGGAGCAGTTG-3' and 5'CATCGCATTGTCTGAGTAGGTGTC-3' for 35 cycles at $94^{\circ} \mathrm{C}$ for $45 \mathrm{~s}, 52^{\circ} \mathrm{C}$ for $1 \mathrm{~min}$, and $72^{\circ} \mathrm{C}$ for $2 \mathrm{~min}$. Homologous recombination at the B3gnt5 locus was confirmed by genomic Southern blotting. Genomic DNA ( 5 $\mu \mathrm{g})$ samples were digested with EcoRI transferred to Hybond-N membranes (GE Healthcare) and hybridized to a 530-bp EcoRI-BstXI genomic fragment (Fig. 2A) as a probe. The detection of a 2.3 -kbp fragment was indicative of a targeted B3gnt5 allele, whereas the wildtype allele was detected as a 3.0-kbp fragment.

\section{Generation and breeding of B3gnt5-targeted mice}

The homologously recombined ES cell clones were karyotyped using the standard potassium chloride method [34]. ES cell clones harboring 40 chromosomes were injected into blastocyst-stage embryos. The resulting chimeric males were bred at 8 weeks of age with $\mathrm{C} 57 \mathrm{BL} / 6$ females and germ-line transmission was observed with the birth of agouti offspring. Mice harboring the targeted B3gnt5 allele were backcrossed for five generations to the C57BL/ 6 background.

\section{Genotyping of mouse samples}

The B3gnt5-wildtype and -null alleles were detected in DNA isolated from tail biopsies, from embryonic-day-10 
(E10) whole embryos and from blastocyst-stage embryos. Blastocysts were harvested from time-mated pregnant females by flushing the uterine horns with M2 buffer (Sigma). The tissue samples were digested with a $25 \mu \mathrm{g} / \mathrm{ml}$ proteinase $\mathrm{K}$ solution at $56^{\circ} \mathrm{C}$ for $16 \mathrm{~h}$ and the reaction was stopped by incubation at $95^{\circ} \mathrm{C}$ for $10 \mathrm{~min}$. The wildtype allele was detected by PCR using the primers 5 'GGCTCAAGATGTCCTCCTCTTA-3' and 5'-ACATGGTCCTGTGGCAAGATTC-3' that yielded a 651-bp fragment. The null allele was detected as a 789-bp PCR fragment using the primers 5'-ACTCGTCAAGAAGGCGATAGAA-3' and 5'-CGGCCATTGAACAAGATGGATT-3'. These PCR reactions were both run for 35 cycles at $94^{\circ} \mathrm{C}$ for $1 \mathrm{~min}$, $60.5^{\circ} \mathrm{C}$ for $45 \mathrm{~s}$, and $72^{\circ} \mathrm{C}$ for $1 \mathrm{~min}$. Another PCR protocol was applied to detect the B3gnt5-null allele in blastocysts. The primers 5'-CATCAGCCGCTACAGTCAAC-3' and 5'-CATCAGAGCAGCCGATTGTC-3' yielded a 326-bp fragment corresponding to a fragment of the PGK-Neo cassette. The corresponding PCR conditions were 35 cycles at $94^{\circ} \mathrm{C}$ for $45 \mathrm{~s}, 63.5^{\circ} \mathrm{C}$ for $40 \mathrm{sec}$, and $72^{\circ} \mathrm{C}$ for 40 S.

\section{Glycosyltransferase activity assays}

$\mathrm{N}$-acetylglucosaminyltransferase activity was assayed in B3gnt5-targeted ES cells as described previously [7]. ES cells $\left(1 \times 10^{7}\right)$ were released by trypsin digest, washed in PBS twice and lyzed in $200 \mu \mathrm{l}$ of $2 \%$ Triton X-100 in 50 $\mathrm{mM}$ cacodylate buffer, $\mathrm{pH} 7.0,20 \mathrm{mM} \mathrm{MnCl}_{2}$ for $15 \mathrm{~min}$ on ice in presence of a protease-inhibitor cocktail (Complete EDTA-free, Roche). Reactions were run at $37^{\circ} \mathrm{C}$ for 4 h using $25 \mu \mathrm{l}$ of post-nuclear supernatant in $50 \mu \mathrm{l}$ reactions of $50 \mathrm{mM}$ cacodylate buffer, $\mathrm{pH} 7.0,20 \mathrm{mM} \mathrm{MnCl}_{2}$, $5 \% \mathrm{Me}_{2} \mathrm{SO}, 0.75 \mathrm{mM}$ ATP, $0.5 \mathrm{mM}$ UDP-GlcNAc including $5 \times 10^{4} \mathrm{cpm}$ of UDP- $\left[{ }^{14} \mathrm{C}\right] \mathrm{GlcNAc}$ (GE Healthcare). Reactions were stopped by adding $500 \mu$ ice-cold $\mathrm{H}_{2} \mathrm{O}$. The reaction products were purified by C18 SepPak cartridges (Waters) and measured by scintillation counting [35].

\section{Isolation of pre-implantation embryos}

Pre-implantation embryos were obtained from superovulated females. Superovulation was carried out by intraperitoneal administration of 50 IU pregnant mare serum gonadotropin (PMSG) (Intervet, Veterinaria AG Zürich, Switzerland) and 25 IU human chorionic gonadotropin (hCG) (Intervet) $48 \mathrm{~h}$ later [36]. Embryos were removed at E1.5 (2-4-cell stage) and E3.5 (blastocyst stage). To obtain embryos at the 4-cell up to the morula stage, 2-cell embryos were cultivated in M16 media (Sigma) until the desired stage was reached. E3.5 blastocysts were isolated by flushing of the uterine horn.

\section{In Situ Hybridization}

Embryos were fixed for $1 \mathrm{~h}$ at room temperature in $4 \%$ paraformaldehyde in PBS and washed twice in PBS/0.1\%
Tween (PBT) and dehydrated once in 25\%, 50\%, 75\% and twice in $100 \%$ methanol/PBT. The dehydration was followed by rehydration in the reverse order of the $\mathrm{MeOH} /$ PBT series $75 \%, 50 \%, 25 \%$ for 5 min each. The embryos were permeabilized in RIPA buffer and refixed in 4\% PFA/ $0.2 \%$ glutaraldehyde. Embryos were washed in a 1:1 mixture of PBT/hybridization solution (50\% formamide, $5 \times$ SSC, $0.1 \%$ Tween-20, $0.1 \%$ SDS, $50 \mu \mathrm{g} / \mathrm{ml}$ E. coli tRNA, $60 \mathrm{mM}$ citric acid) for $10 \mathrm{~min}$ and then in hybridization solution. In situ hybridization was performed as described previously [37]. As a control for the specificity of the labelings in each hybridization experiment, control embryos were hybridized with an equal concentration of a sense probe transcribed from the same template as the antisense probe. After staining over night at $4{ }^{\circ} \mathrm{C}$, embryos were post fixed in $4 \%$ paraformaldehyde/0.1\% glutaraldehyde in PBT for $1 \mathrm{~h}$ and washed twice in PBT, then cleared in glycerol: PBT (1:1) and stored in glycerol: $2 \mathrm{mM}$ EDTA in PBT (4:1). Hybridization results were documented using a Zeiss Axiovert $200 \mathrm{M}$ microscope (Carl Zeiss AG, Feldbach, Switzerland). The B3gnt5 908-bp riboprobes were prepared as described previously [7]. T7 and SP6 riboprobes were made using a DIG RNA labeling kit (Roche, Switzerland) and alkaline hydrolyzed to reduce the size of the riboprobes to about $300 \mathrm{bp}$.

\section{Glycosphingolipid analysis}

GSL were extracted from mouse ES cells three times with chloroform:methanol:water (4:8:3, v:v:v) [38]. The extracts were pooled, dried under $\mathrm{N}_{2}$ and re-dissolved in chloroform:methanol:PBS (1:163:160, v:v:v). A 1 ml SepPak tC18 cartridge (Waters) was conditioned with $2 \mathrm{ml}$ methanol and $2 \mathrm{ml}$ water. The dissolved lipid extract, corresponding to $50 \mathrm{mg}$ wet weight of cell pellets were applied to the SepPak tC18 cartridge, followed by washing with $3 \mathrm{ml}$ water. GSL were eluted with $1 \mathrm{ml}$ chloroform:methanol $(98: 2, \mathrm{v}: \mathrm{v}), 2 \mathrm{ml}$ chloroform:methanol $(1: 3, \mathrm{v}: \mathrm{v})$ and $1 \mathrm{ml}$ methanol [39]. Eluates were dried under $\mathrm{N}_{2}$ and subjected to ceramide glycanase digestion, 2-aminobenzamide-labelling and NP-HPLC analysis as described earlier [40]. One minute fractions were collected from the NP-HPLC and aliquots were subjected either directly or after desalting with $100 \mu \mathrm{l}$ custom packed graphite columns (ENVI-Carb, Supelco) to MALDI-MS.

\section{Mass Spectrometry}

The MALDI matrix was prepared by suspending $10 \mathrm{mg}$ DHB in $1 \mathrm{ml}$ of $50 \%$ acetonitrile, containing $1 \mathrm{mM} \mathrm{NaCl}$. Sample and matrix were mixed on the MALDI plate at a ratio of $1: 1$ and allowed to dry at room temperature. The dried spots were re-crystallized by applying $<0.1 \mu$ l ethanol. MALDI mass spectra were recorded in positive ion mode, using an Applied Biosystems 4800 Proteomics Analyzer (Applied Biosystems). Averages of 2000 to 5000 
laser shots were used to obtain MS/MS spectra. The collision energy was set at $1 \mathrm{kV}$ and the air pressure inside the collision cell was set at $2 \times 10^{-6}$ Torr.

\section{Authors' contributions}

FB screened ES cells for homologous recombination characterized positive ES cell clones, was responsible for mouse breeding and phenotyping, and participated to manuscript preparation. AJH extracted and analyzed GSL profiles in ES cells and participated to manuscript preparation. DZ constructed the B3gnt5 targeting vector, characterized homologous recombinant ES cell clones and participated to manuscript preparation. PC assisted FB and contributed to embryo isolation, fixation and in situ hybridization, and participated to manuscript preparation. TH initiated and directed the study, participated to the genotype analysis of mouse embryos, and wrote most of the manuscript. All authors read and approved the final manuscript.

\section{Acknowledgements}

We thank Dr. Birgit Ledermann from the Institute of Laboratory Animal Science, University of Zürich for her technical assistance with the ES cell culture and the Functional Genomic Center Zurich (FGCZ), Switzerland and Dr. P. Gehrig, FGCZ for their support with the MALDI-TOF-TOFmass spectrometer. This research was supported by the Swiss National Science Foundation Grants PPO0A-106756 and 3100A0-1/6039 to TH.

\section{References}

I. Levery SB: Glycosphingolipid structural analysis and glycosphingolipidomics. Methods Enzymol 2005, 405:300-69.

2. Kitamura M, Takamiya K, Aizawa S, Furukawa K: Gangliosides are the binding substances in neural cells for tetanus and botulinum toxins in mice. Biochim Biophys Acta 1999, I44I:I-3.

3. Furukawa K, Tokuda N, Okuda T, Tajima O, Furukawa K: Glycosphingolipids in engineered mice: insights into function. Seminars in Cell \& Developmental Biology 2004, 15:389-396.

4. Solter $D$, Knowles $B B$ : Monoclonal antibody defining a stagespecific mouse embryonic antigen (SSEA-I). Proc Natl Acad Sci USA 1978, 75:5565-9.

5. Solter D, Knowles BB: Developmental stage-specific antigens during mouse embryogenesis. Curr Top Dev Biol 1979, I3(Pt I): $139-65$.

6. Shevinsky LH, Knowles BB, Damjanov I, Solter D: Monoclonal antibody to murine embryos defines a stage-specific embryonic antigen expressed on mouse embryos and human teratocarcinoma cells. Cell 1982, 30:697-705.

7. Henion TR, Zhou D, Wolfer DP, Jungalwala FB, Hennet T: Cloning of a mouse $\beta I, 3 \quad \mathbf{N}$-acetylglucosaminyltransferase Glc$\operatorname{NAc}(\beta \mid, 3) \mathrm{Gal}(\beta I, 4) \mathrm{Glc}$-ceramide synthase gene encoding the key regulator of lacto-series glycolipid biosynthesis. J Biol Chem 200I, 276:3026I-30269.

8. Togayachi A, Akashima T, Ookubo R, Kudo T, Nishihara S, Iwasaki H, Natsume A, Mio H, Inokuchi J-i, Irimura T, et al: Molecular cloning and characterization of UDP-GIcNAc:lactosylceramide $\beta I, 3-$ $\mathrm{N}$-acetylglucosaminyltransferase $(\beta 3 \mathrm{Gn}-\mathrm{T5})$, an essential enzyme for the expression of HNK-I and Lewis $X$ epitopes on glycolipids. J Biol Chem 200I, 276:22032-22040.

9. Chou $D$, Jungalwala $F$ : $\mathbf{N}$-acetylglucosaminyltransferase regulates the expression of neolactoglycolipids including sulfoglucuronylglycolipids in the developing nervous system. J Biol Chem 1993, 268:21727-21733.

10. Chou KH, llyas AA, Evans JE, Quarles RH, Jungalwala FB: Structure of a glycolipid reacting with monoclonal IgM in neuropathy and with HNK-I. Biochem Biophys Res Commun I 985, I 28:383-8.
II. Chou DK, llyas AA, Evans JE, Costello C, Quarles RH, Jungalwala FB: Structure of sulfated glucuronyl glycolipids in the nervous system reacting with HNK-I antibody and some IgM paraproteins in neuropathy. I Biol Chem 1986, 26 I: I I7I7-25.

12. Ariga T, Kohriyama T, Freddo L, Latov N, Saito M, Kon K, Ando S, Suzuki M, Hemling ME, Rinehart KL Jr, et al.: Characterization of sulfated glucuronic acid containing glycolipids reacting with IgM M-proteins in patients with neuropathy. J Biol Chem 1987, 262:848-53.

13. Chou DK, Flores S, Jungalwala FB: Expression and regulation of UDP-glucuronate: neolactotetraosylceramide glucuronyltransferase in the nervous system. I Biol Chem |99|, 266: 1794I-7.

14. Senn C, Kutsche M, Saghatelyan A, Bosl MR, Lohler J, Bartsch U, Morellini F, Schachner M: Mice deficient for the HNK-I sulfotransferase show alterations in synaptic efficacy and spatial learning and memory. Mol Cell Neurosci 2002, 20:712-29.

15. Yamamoto S, Oka S, Inoue M, Shimuta M, Manabe T, Takahashi H, Miyamoto M, Asano M, Sakagami J, Sudo K, et al.: Mice deficient in nervous system-specific carbohydrate epitope HNK-I exhibit impaired synaptic plasticity and spatial learning. J Biol Chem 2002, 277:27227-31.

16. Chou DKH, Jungalwala FB: $\mathbf{N}$-acetylglucosaminyl transferase regulates the expression of the sulfoglucuronyl glycolipids in specific cell types in cerebellum during development. J Biol Chem 1996, 27I:28868-28874.

17. Muramatsu T, Muramatsu H: Carbohydrate antigens expressed on stem cells and early embryonic cells. Glycoconj J 2004, 2I:4I-5

18. Kudo T, Kaneko M, Iwasaki H, Togayachi A, Nishihara S, Abe K, Narimatsu $\mathrm{H}$ : Normal embryonic and germ cell development in mice lacking $\alpha$ I,3-Fucosyltransferase IX (Fut9) which show disappearance of stage-specific embryonic antigen I. Mol Cell Biol 2004, 24:422I-4228.

19. Grubenmann CE, Frank CG, Hülsmeier AJ, Schollen E, Matthijs G, Mayatepek E, Berger EG, Aebi M, Hennet T: Deficiency of the first mannosylation step in the $\mathbf{N}$-glycosylation pathway causes congenital disorder of glycosylation type Ik. Hum Mol Genet 2004, 13:535-542.

20. Fenderson BA, Zehavi U, Hakomori S: A multivalent lacto-Nfucopentaose III-lysyllysine conjugate decompacts preimplantation mouse embryos, while the free oligosaccharide is ineffective. J Exp Med 1984, 160:1591-6.

21. Nakayama F, Nishihara S, Iwasaki H, Kudo T, Okubo R, Kaneko M, Nakamura M, Karube M, Sasaki K, Narimatsu H: CDI 5 expression in mature granulocytes is determined by alpha I,3-fucosyltransferase IX, but in promyelocytes and monocytes by alpha I,3-fucosyltransferase IV. I Biol Chem 200I, 276:16100-6.

22. Yamashita T, Wada R, Sasaki T, Deng C, Bierfreund U, Sandhoff K, Proia RL: A vital role for glycosphingolipid synthesis during development and differentiation. Proceedings of the National Academy of Sciences of the United States of America 1999, 96:9|42-9|47.

23. Keusch JJ, Manzella SM, Nyame KA, Cummings RD, Baenziger JU: Cloning of Gb3 Synthase, the key enzyme in globo-series glycosphingolipid synthesis, predicts a family of $\alpha$ l,4-glycosyltransferases conserved in plants, insects, and mammals. J Biol Chem 2000, 275:253I5-2532I.

24. Okajima T, Nakamura Y, Uchikawa M, Haslam DB, Numata SI, Furukawa $\mathrm{K}$, Urano T, Furukawa K: Expression cloning of human globoside synthase cDNAs. Identification of $\beta 3 \mathrm{Gal}-T 3$ as UDP. $\mathbf{N}$-acetylgalactosamine:globotriaosylceramide $\quad \beta I, 3-N$ acetylgalactosaminyltransferase. J Biol Chem 2000, 275:40498-40503.

25. Okuda T, Tokuda N, Numata S, Ito M, Ohta M, Kawamura K, Wiels J, Urano T, Tajima O, Furukawa K: Targeted disruption of Gb3/ CD77 synthase gene resulted in the complete deletion of globo-series glycosphingolipids and loss of sensitivity to verotoxins. J Biol Chem 2006, 28 I: 10230-5.

26. Vollrath B, Fitzgerald KJ, Leder P: A murine homologue of the drosophila brainiac gene shows homology to glycosyltransferases and is required for preimplantation development of the mouse. Mol Cell Biol 200I, 21:5688-5697.

27. Yamashita T, Wada R, Proia RL: Early developmental expression of the gene encoding glucosylceramide synthase, the 
enzyme controlling the first committed step of glycosphingolipid synthesis. Biochim Biophys Acta 2002, 1573:236-40.

28. Furukawa K, Takamiya K, Okada M, Inoue M, Fukumoto S: Novel functions of complex carbohydrates elucidated by the mutant mice of glycosyltransferase genes. Biochim Biophys Acta 200I, I525:I-12.

29. Togayachi A, Kozono $\mathrm{Y}$, Ishida $\mathrm{H}$, Abe S, Suzuki N, Tsunoda $\mathrm{Y}$, Hagiwara $K$, Kuno $A$, Ohkura $T$, Sato $N$, et al.: Polylactosamine on glycoproteins influences basal levels of lymphocyte and macrophage activation. Proc Natl Acad Sci USA 2007, 104: 15829-34.

30. Giraudo CG, Daniotti JL, Maccioni HJ: Physical and functional association of glycolipid $\mathbf{N}$-acetyl-galactosaminyl and galactosyl transferases in the Golgi apparatus. Proc Natl Acad Sci USA 2001, 98:1625-30.

31. Pham CT, Macivor DM, Hug BA, Heusel JW, Ley TJ: Long-range disruption of gene expression by a selectable marker cassette. Proc Natl Acad Sci USA 1996, 93: I 3090-I 3095

32. Nagy A, Rossant J, Nagy R, Abramov-Newerly W, Roder JC: Derivation of completely cell culture-derived mice from early passage embryonic stem cells. Proc Natl Acad Sci USA 1993 90:8424-8428.

33. Deng C, Wynshaw-Boris A, Zhou F, Kuo A, Leder P: Fibroblast growth factor receptor 3 is a negative regulator of bone growth. Cell 1996, 84:91I-2I.

34. Ledermann B, Burki K: Establishment of a germ-line competent C57BL/6 embryonic stem cell line. Exp Cell Res 199I, 197:254-8.

35. Hennet T, Dinter A, Kuhnert P, Mattu TS, Rudd PM, Berger EG: Genomic cloning and expression of three murine UDPgalactose: $\beta-\mathrm{N}$-acetylglucosamine $\beta$ I,3-galactosyltransferase genes. J Biol Chem 1998, 273:58-65.

36. Hoogan B, Beddington R, Constantini F, Lacy E: Manipulating the Mouse Embryo: A Laboratory Manual. 1994.

37. Wilkinson DG: Whole-mount in situ hybridization of vertebrate embryos. Oxford: IRL Press; 1992.

38. Svennerholm L, Fredman P: A procedure for the quantitative isolation of brain gangliosides. Biochim Biophys Acta 1980, 617:97-109.

39. Neville DC, Coquard V, Priestman DA, te Vruchte DJ, Sillence DJ, Dwek RA, Platt FM, Butters TD: Analysis of fluorescently labeled glycosphingolipid-derived oligosaccharides following ceramide glycanase digestion and anthranilic acid labeling. Anal Biochem 2004, 33 I:275-82.

40. Müller R, Hülsmeier AJ, Altmann F, Ten Hagen K, Tiemeyer M, Hennet $T$ : Characterization of mucin-type core-I beta $I-3$ galactosyltransferase homologous enzymes in Drosophila melanogaster. Febs J 2005, 272:4295-305.
Publish with Bio Med Central and every scientist can read your work free of charge

"BioMed Central will be the most significant development for disseminating the results of biomedical research in our lifetime. "

Sir Paul Nurse, Cancer Research UK

Your research papers will be:

- available free of charge to the entire biomedical community

- peer reviewed and published immediately upon acceptance

- cited in PubMed and archived on PubMed Central

- yours - you keep the copyright
BioMedcentral 